\title{
BODY COMPOSITION AND POSTURAL STABILITY IN GOALKEEPERS OF THE POLISH NATIONAL JUNIOR HANDBALL TEAM
}

\author{
JACEK WILCZYŃSKI \\ Jan Kochanowski University in Kielce, Faculty of Medicine and Health Sciences, \\ Department of Posturology, Hearing and Balance Rehabilitation, Kielce, Poland
}

\author{
Mailing address: Jan Kochanowski University in Kielce, Faculty of Medicine and Health Sciences, \\ Department of Posturology, Hearing and Balance Rehabilitation, 19 IX Wieków Kielc Ave., 25-317 Kielce, \\ tel.: +48 41 3496954, fax: +48 41 3497201, e-mail: jwilczyński@onet.pl
}

\begin{abstract}
Introduction. The aim of the study was to assess the relationship between the body composition and postural stability of goalkeepers representing the Polish National Junior Handball Team. Material and methods. Body composition was assessed by means of bioelectrical impedance analysis. Postural stability was examined using the AccuGait AMTI force platform. Results. The body composition of the subjects was correct. All of the subjects had very good postural stability. Postural sway was higher in the sagittal plane than in the frontal one. Path Length and Average COP Speed were significantly increased during the closedeyes trial. Only Fat Mass (\%) and Fat Mass $(\mathrm{kg})$ were significantly directly correlated with Area Ellipse $\left(\mathrm{cm}^{2}\right)(\mathrm{OE}$, open eyes). Inverse correlations occurred between Fat-Free Mass $(\mathrm{kg})$ and Average Load Point $Y(\mathrm{~cm})(\mathrm{OE})$ as well as Average Load Point $Y$ $(\mathrm{cm})(\mathrm{CE}$, closed eyes). Muscle Mass (kg) was significantly inversely correlated with Average Load Point Y (cm) (OE) and also with Average Load Point Y (cm) (CE). Body Mass Index correlated negatively only with Average Load Point Y (cm) (CE). Total Body Water $(\mathrm{kg})$ was significantly inversely correlated with Average Load Point Y (cm) (OE) and also with Average Load Point Y (cm) (CE). However, Total Body Water (\%) only correlated negatively with Area Ellipse $\left(\mathrm{cm}^{2}\right)(\mathrm{OE})$. Conclusions. Postural stability was determined by the composition and structure of the body. Single-sided sports specialisation can lead to static disorders of the body during the developmental period discussed. Therefore, systematic tests are needed to monitor the body composition and postural stability of handball goalkeepers.
\end{abstract}

Key words: body composition, postural stability, AccuGait AMTI force platform, goalkeepers of the Polish National Junior Handball Team

\section{Introduction}

The systematic increase in the level and intensity of the training process of handball goalkeepers requires thorough medical examination during recruitment and, then, permanent medical supervision. Medical examinations are aimed at securing the optimal health of young athletes. There is also a need to assess the impact of systematically increased and differently directed physical loads on a young developing body [1-5].

Body composition analysis is one of the most important elements of health assessment in sport. Knowledge about the ontogenetic variability of body composition traits contributes to a more accurate understanding of the physiological and biochemical processes taking place in the body. Knowledge of these issues can significantly help both in the recruitment and training processes of handball goalkeepers. During the developmental period, body structure and composition are subject to multiple changes resulting from the processes of growth and differentiation, which are genetically determined and modified by environmental factors. Body composition analyses should involve morphological and structural assessments. Attention should also be paid to chemical and tissue composition and components in the somatotype. Undoubtedly, the shape and form of the body are most importantly influenced by its two main so-called plasticisers, muscular and fat tissue, and the third fundamental factor - the skeletal system [6-11].

The composition of the body affects its structure and this, in turn, is related to its stability. The physical activity of a handball goalkeeper manifests itself in motor actions, which also include stabilisation of the body. It is a starting base for locomotion and determines the mobility of a goalkeeper. The body can retain its vertical position in space as long as the projection of the centre of gravity remains inside the base area. The mechanical stability of the body, that is its sensitivity to external forces, primarily depends on its mass and shape, and in particular, on the ratio of height to the radius of the posture [12-14].

Body mass, body height, and the size of the support surface are determinants of static mechanical stability. The higher the body mass, the lower the centre of gravity, and the greater the support area, the more stable the standing position. The problem of dynamic stability is different [15-17]. Recovering lost stability requires much more efficiency of the muscular system. In this case, the increase in inertia associated with excessive body mass worsens stability. Stability is maintained by constant or phase tension of the postural muscles, whose activity is controlled by both central and peripheral signals. The resultant of this control is the position of the centre of gravity of the body. Most often, it is assumed that posture control consists in regu- 
lating the position of the body's centre of gravity. Correct and stable posture is a prerequisite for the performance of most free movements and locomotion, and plays a major role in a handball goalkeeper's performance [18, 19]. In light of the above, the aim of research was to assess the body composition and postural stability of goalkeepers representing the Polish National Junior Handball Team.

\section{Material and methods}

Eleven junior goalkeepers of the Polish National Handball Team aged 15-19 took part in the research. The research project was carried out in 2014-2018 at the Posturological Laboratory at the Faculty of Medicine of Jan Kochanowski University in Kielce (Poland). At the time of the study, the goalkeepers had been practising handball for 5 to 10 years. Training sessions were held every day for one and a half hours. The tests were non-invasive and completely safe. All the participants gave their written consent to participate in the study. The research procedures were carried out in accordance with the 1964 Declaration of Helsinki and with the consent of the University Bioethics Committee for Scientific Research. Body composition was assessed using bioelectrical impedance analysis (BIA), which consisted in examining the resistance of the electric current flowing through the tissues. This analysis uses knowledge about the prevalence of electrolytes and better electrical conductivity of muscle tissue, which has a significant amount of water. Adipose tissue, on the other hand, is characterised by greater inhibition in the flow of electricity. BIA is a reliable, non-invasive, and easily accessible means for assessing the parameters of body composition. The Tanita MC 780 MA body composition analyser was used as a research tool. The following body composition variables were measured: Body Mass (kg), Body Mass Index, Fat Mass (\%), Fat Mass (kg), Fat-Free Mass (kg), Muscle Mass (kg), Total Body Water (kg), and Total Body Water (\%).

The AccuGait AMTI platform was used to assess postural stability, together with the Balance Clinic software. The standard free standing stability test, that is the Romberg test, was performed. It consisted of two successive 30-second trials. The first one was carried out with open eyes (OE) and the second with closed eyes (CE). The measurement on the platform consisted in the continuous observation of centre-of-foot pressure (COP). Recording the body's deflection made it possible to obtain accurate information on postural stability. The COP movements reflected the movements of the centre of mass of the body (COM) in the frontal and sagittal planes. We analysed the following: Average Load Point X $(\mathrm{cm})$, which determined the lateral coordinates X; Average Load Point Y $(\mathrm{cm})$, which determined the anterior-posterior coordinates Y; Path Length $(\mathrm{cm})$, that is the COP route length during the test; Average COP Speed $(\mathrm{cm} / \mathrm{sec})$, which was the speed of COP movement during the test; and Area Ellipse $\left(\mathrm{cm}^{2}\right)$, that is the area determined by the COP during the test. Less stable individuals have higher values of all the parameters mentioned. The normality of variable distribution

Table 1. Characteristics of body composition and postural stability

\begin{tabular}{|c|c|c|c|c|c|c|c|}
\hline Body composition variables & Mean & Standard deviation & Minimum & Lower quartile & Median & Upper quartile & Maximum \\
\hline Age (years) & 16.82 & 1.60 & 15.00 & 15.00 & 17.00 & 19.00 & 19.00 \\
\hline Body height $(\mathrm{cm})$ & 191.27 & 3.10 & 187.00 & 188.00 & 191.00 & 194.00 & 196.00 \\
\hline Body mass (kg) & 88.41 & 12.26 & 63.00 & 78.70 & 92.70 & 95.70 & 107.20 \\
\hline Fat Mass (\%) & 16.71 & 4.12 & 10.70 & 14.30 & 15.10 & 19.40 & 24.50 \\
\hline Fat Mass (kg) & 15.01 & 5.14 & 8.90 & 9.90 & 14.00 & 18.20 & 23.90 \\
\hline Fat-Free Mass (kg) & 73.40 & 8.90 & 54.00 & 65.70 & 78.20 & 79.50 & 83.30 \\
\hline Muscle Mass (kg) & 69.77 & 8.49 & 51.30 & 62.40 & 74.40 & 75.60 & 79.20 \\
\hline BMI & 24.18 & 3.22 & 17.30 & 22.50 & 24.70 & 27.30 & 27.90 \\
\hline Total Body Water (kg) & 53.42 & 6.40 & 39.50 & 48.10 & 56.90 & 57.60 & 61.00 \\
\hline Total Body Water (\%) & 60.62 & 2.75 & 55.30 & 59.00 & 61.80 & 62.70 & 63.60 \\
\hline $\begin{array}{c}\text { Postural stability variables } \\
\text { (AccuGait AMTI) }\end{array}$ & Mean & Standard deviation & Minimum & Lower quartile & Median & Upper quartile & Maximum \\
\hline Average Load Point X (cm) (OE) & 0.80 & 0.36 & 0.33 & 0.49 & 0.77 & 1.13 & 1.49 \\
\hline Average Load Point $\mathrm{Y}(\mathrm{cm})(\mathrm{OE})$ & 5.41 & 1.70 & 2.87 & 4.41 & 5.04 & 6.14 & 9.30 \\
\hline Path Length (OE) & 52.64 & 8.74 & 42.07 & 47.43 & 50.24 & 59.25 & 72.19 \\
\hline Average COP Speed (cm/sec) (OE) & 1.75 & 0.29 & 1.40 & 1.58 & 1.68 & 1.98 & 2.41 \\
\hline Area Ellipse $(\mathrm{cm})(\mathrm{OE})$ & 6.28 & 2.43 & 1.61 & 4.45 & 6.10 & 7.94 & 10.86 \\
\hline Average Load Point X (cm) (CE) & 0.55 & 0.61 & 0.01 & 0.22 & 0.29 & 0.58 & 2.03 \\
\hline Average Load Point Y (cm) (CE) & 4.81 & 1.43 & 3.51 & 3.77 & 4.36 & 5.19 & 8.66 \\
\hline Path Length $(\mathrm{cm})(\mathrm{CE})$ & 69.39 & 19.43 & 40.55 & 57.89 & 65.70 & 86.40 & 103.82 \\
\hline Average COP Speed (cm/sec) (CE) & 2.31 & 0.65 & 1.35 & 1.93 & 2.19 & 2.88 & 3.46 \\
\hline Area Ellipse (cm) (CE) & 6.64 & 2.53 & 3.40 & 3.82 & 6.37 & 8.23 & 11.60 \\
\hline Average Load Point $X(\mathrm{~cm})(\mathrm{OE}-\mathrm{CE})$ & 0.24 & 0.41 & -0.53 & -0.12 & 0.41 & 0.63 & 0.64 \\
\hline Average Load Point Y (cm) (OE-CE) & 0.60 & 0.65 & -0.64 & 0.21 & 0.64 & 0.97 & 1.68 \\
\hline Path length $(\mathrm{cm})(\mathrm{OE}-\mathrm{CE})$ & -16.76 & 15.48 & -44.57 & -32.60 & -15.46 & -4.57 & 7.92 \\
\hline Average COP Speed (cm/sec) (OE-CE) & -0.56 & 0.52 & -1.49 & -1.09 & -0.52 & -0.15 & 0.26 \\
\hline Area Ellipse $(\mathrm{cm})(\mathrm{OE}-\mathrm{CE})$ & -0.36 & 2.66 & -6.63 & -1.57 & -0.65 & 1.05 & 4.12 \\
\hline
\end{tabular}


Table 2. Romberg test results

\begin{tabular}{|c|c|c|c|c|c|c|}
\hline \multirow{2}{*}{ Postural stability variables } & \multicolumn{2}{|c|}{ Open eyes } & \multicolumn{2}{|c|}{ Closed eyes } & \multirow{2}{*}{ Difference } & \multirow{2}{*}{ Student's t-test } \\
\hline & Mean & SD & Mean & SD & & \\
\hline Average Load Point X (cm) & 0.80 & 0.36 & 0.55 & 0.61 & 0.24 & $t=1.98 ; p=0.0752$ \\
\hline Average Load Point $Y(\mathrm{~cm})$ & 5.41 & 1.70 & 4.81 & 1.43 & 0.60 & $t=3.04 ; p=0.0124$ \\
\hline Path length $(\mathrm{cm})$ & 52.64 & 8.74 & 69.39 & 19.43 & -16.76 & $t=3.59 ; p=0.0049$ \\
\hline Average COP Speed (cm/sec) & 1.75 & 0.29 & 2.31 & 0.65 & -0.56 & $t=3.59 ; p=0.0049$ \\
\hline Area Ellipse $(\mathrm{cm})$ & 6.28 & 2.43 & 6.64 & 2.53 & -0.36 & $t=0.44 ; p=0.6658$ \\
\hline
\end{tabular}

Table 3. Correlations between variables of body composition and AccuGait AMTI variables

\begin{tabular}{|c|c|c|c|c|c|c|c|}
\hline $\begin{array}{l}\text { Postural stability } \\
\text { variables }\end{array}$ & Fat Mass (\%) & Fat Mass (kg) & $\begin{array}{l}\text { Fat-Free Mass } \\
\text { (kg) }\end{array}$ & $\begin{array}{l}\text { Muscle Mass } \\
(\mathrm{kg})\end{array}$ & $\begin{array}{l}\text { Body Mass } \\
\text { Index }\end{array}$ & $\begin{array}{l}\text { Total Body } \\
\text { Water (kg) }\end{array}$ & $\begin{array}{l}\text { Total Body } \\
\text { Water (\%) }\end{array}$ \\
\hline \multirow{2}{*}{$\begin{array}{l}\text { Average Load Point X } \\
\qquad(\mathrm{cm})(\mathrm{OE})\end{array}$} & 0.1013 & 0.2273 & 0.2229 & 0.2221 & 0.1585 & 0.2458 & -0.0787 \\
\hline & $p=0.767$ & $p=0.502$ & $p=0.510$ & $p=0.512$ & $p=0.642$ & $p=0.466$ & $p=0.818$ \\
\hline \multirow{2}{*}{$\begin{array}{l}\text { Average Load Point Y } \\
\qquad(\mathrm{cm})(\mathrm{OE})\end{array}$} & 0.0566 & -0.1627 & -0.6767 & -0.6769 & -0.5889 & -0.6600 & 0.0124 \\
\hline & $p=0.869$ & $p=0.633$ & $p=0.022$ & $p=0.022$ & $p=0.057$ & $p=0.027$ & $p=0.971$ \\
\hline \multirow{2}{*}{ Path Length $(\mathrm{OE})$} & 0.2835 & 0.1088 & -0.5019 & -0.5016 & -0.3051 & -0.4944 & -0.2532 \\
\hline & $p=0.398$ & $p=0.750$ & $p=0.116$ & $p=0.116$ & $p=0.362$ & $p=0.122$ & $p=0.453$ \\
\hline \multirow{2}{*}{$\begin{array}{l}\text { Average COP Speed } \\
\quad(\mathrm{cm} / \mathrm{sec})(\mathrm{OE})\end{array}$} & 0.2835 & 0.1088 & -0.5018 & -0.5015 & -0.3050 & -0.4943 & -0.2531 \\
\hline & $p=0.398$ & $p=0.750$ & $p=0.116$ & $p=0.116$ & $p=0.362$ & $p=0.122$ & $p=0.453$ \\
\hline \multirow{2}{*}{ Area Ellipse $\left(\mathrm{cm}^{2}\right)(\mathrm{OE})$} & 0.7137 & 0.6776 & 0.1281 & 0.1275 & 0.4642 & 0.1560 & -0.6941 \\
\hline & $p=0.014$ & $p=0.022$ & $p=0.707$ & $p=0.709$ & $p=0.150$ & $p=0.647$ & $p=0.018$ \\
\hline \multirow{2}{*}{$\begin{array}{l}\text { Average Load Point X } \\
\qquad(\mathrm{cm})(\mathrm{CE})\end{array}$} & 0.0132 & 0.2081 & 0.3841 & 0.3849 & 0.2358 & 0.3718 & -0.0782 \\
\hline & $p=0.969$ & $p=0.539$ & $p=0.244$ & $p=0.242$ & $p=0.485$ & $p=0.260$ & $p=0.819$ \\
\hline \multirow{2}{*}{$\begin{array}{l}\text { Average Load Point } Y \\
\qquad(\mathrm{~cm})(\mathrm{CE})\end{array}$} & -0.1449 & -0.3410 & -0.7008 & -0.7007 & -0.7208 & -0.6975 & 0.2011 \\
\hline & $p=0.671$ & $p=0.305$ & $p=0.016$ & $p=0.016$ & $p=0.012$ & $p=0.017$ & $p=0.553$ \\
\hline \multirow{2}{*}{ Path Length $(\mathrm{cm})(\mathrm{CE})$} & 0.0340 & 0.0162 & -0.1021 & -0.1006 & -0.0312 & -0.1439 & -0.1311 \\
\hline & $p=0.921$ & $p=0.962$ & $p=0.765$ & $p=0.768$ & $p=0.927$ & $p=0.673$ & $p=0.701$ \\
\hline \multirow{2}{*}{$\begin{array}{l}\text { Average COP Speed } \\
\quad(\mathrm{cm} / \mathrm{sec})(\mathrm{CE})\end{array}$} & 0.0340 & 0.0162 & -0.1020 & -0.1005 & -0.0312 & -0.1439 & -0.1311 \\
\hline & $p=0.921$ & $p=0.962$ & $p=0.765$ & $p=0.769$ & $p=0.928$ & $p=0.673$ & $p=0.701$ \\
\hline \multirow{2}{*}{ Area Ellipse $(\mathrm{cm})(\mathrm{OE})$} & 0.1613 & 0.1692 & 0.0041 & 0.0048 & 0.1165 & -0.0327 & -0.2658 \\
\hline & $p=0.636$ & $p=0.619$ & $p=0.991$ & $p=0.989$ & $p=0.733$ & $p=0.924$ & $p=0.429$ \\
\hline
\end{tabular}

was determined using the Shapiro-Wilk test. Differences found for the variables in the Romberg test (OE-CE) were analysed using Student's t-test. Relationships between body composition and postural stability were tested with Pearson's correlation coefficient. Statistical significance was set at $\mathrm{p}<0.05$.

\section{Results}

The subjects were characterised by high height. The average height was $191.27 \mathrm{~cm}$, and the standard deviation was 3.1. The subjects' Body Mass (kg) was on average 88.41, and the standard deviation was 12.26. The BMI result was 24.18 on average, with a standard deviation of 3.22. The high though normal BMI value was associated with high muscle mass. Fat Mass (\%) was 16.71, with a standard deviation of 4.12. However, the mean value for Fat Mass (kg) was 15.01, the standard deviation being 5.14. Fat-Free Mass (kg) was 73.4, with a standard deviation of 8.9. Muscle Mass (kg) had a mean value of 69.77 , with a standard deviation of 8.49. Total Body Water $(\mathrm{kg})$ amounted to 53.42 on average, the standard deviation being 6.4. Total Body Water (\%) averaged at 60.62, and the standard deviation for this variable was 2.75 (Tab. 1).

In the postural stability test on the AccuGait AMTI platform, Average Load Point X $(\mathrm{cm})$ oscillated from 0.8 with open eyes (OE) to 0.55 with eyes closed (CE). The difference in the Romberg test was 0.24 . This parameter was not significantly different between the measurement with open and closed eyes $(\mathrm{t}=1.98, \mathrm{df}=10, \mathrm{p}=0.0752)$. Average Load Point $\mathrm{Y}(\mathrm{cm})$ oscillated from 5.41 with open eyes to 4.81 with eyes closed, the difference in the Romberg test being 0.6. This parameter was also not significantly different between the measurement with open and closed eyes $(t=3.04, \mathrm{df}=10, \mathrm{p}=0.0124)$. Path Length (cm) fluctuated from 52.64 with eyes open to 69.39 with eyes closed, with a -16.76 difference in the Romberg test. This parameter increased significantly in the closed-eyes test $(t=3.59$, $\mathrm{df}=10, \mathrm{p}=0.0049)$. Average COP Speed $(\mathrm{cm} / \mathrm{sec})$ oscillated 
from 1.75 with open eyes to 2.31 with eyes closed; the difference in the Romberg test was -0.56 . This parameter increased significantly in the closed eyes test $(t=3.59, \mathrm{df}=10, \mathrm{p}=0.0049)$. Area Ellipse $\left(\mathrm{cm}^{2}\right)$ oscillated from 6.28 with open eyes to 6.64 with eyes closed, the difference in the Romberg test being -0.36 . This parameter was not significantly different between the measurement with open and closed eyes $(\mathrm{t}=0.44, \mathrm{df}=10, \mathrm{p}=0.6658)$ (Tab. 1, 2).

Fat Mass (\%) was significantly directly correlated with Area Ellipse $\left(\mathrm{cm}^{2}\right)(\mathrm{OE})(\mathrm{R}=0.7137, \mathrm{p}=0.014)$. Fat Mass $(\mathrm{kg})$ was also significantly directly correlated with Area Ellipse $\left(\mathrm{cm}^{2}\right)$ $(\mathrm{OE})(\mathrm{R}=0.6776, \mathrm{p}=0.022)$. Inverse correlations occurred between Fat-Free Mass $(\mathrm{kg})$ and Average Load Point Y (cm) (OE) $(\mathrm{R}=-0.6767, \mathrm{p}=0.022)$ as well as Average Load Point $\mathrm{Y}(\mathrm{cm})$ (CE) $(\mathrm{R}=-0.7008, \mathrm{p}=0.016)$. Muscle Mass $(\mathrm{kg})$ was significantly inversely correlated with Average Load Point Y $(\mathrm{cm})(\mathrm{OE})$ $(\mathrm{R}=-0.6769, \mathrm{p}=0.022)$ and also with Average Load Point $\mathrm{Y}(\mathrm{cm})$ (CE) $(\mathrm{R}=-0.7007, \mathrm{p}=0.016)$. Body Mass Index correlated negatively only with Average Load Point Y (cm) $(\mathrm{CE})(\mathrm{R}=-0.7208$, $\mathrm{p}=0.012)$. In contrast, Total Body Water $(\mathrm{kg})$ was significantly inversely correlated with Average Load Point Y (cm) (OE) $(\mathrm{R}=-0.6600, \mathrm{p}=0.027)$ and additionally with Average Load Point $Y(\mathrm{~cm})(\mathrm{CE})(\mathrm{R}=-0.6975, \mathrm{p}=0.017)$. However, Total Body Water $(\%)$ only correlated negatively with Area Ellipse $\left(\mathrm{cm}^{2}\right)$ (OE) $(\mathrm{R}=-0.6941, \mathrm{p}=0.018)(\mathrm{Tab} .3)$.

\section{Discussion}

The goalkeeper plays an important role in a handball team's performance. His/her movements must be coordinated and as simple and economical as possible. The short distance from the players attacking his/her goal requires reflex and courage, but also the ability to predict the flight of the ball and cooperate with the defence. A goalkeeper should move appropriately, assume suitable positions, and have a general feeling for the game. Movement coordination, and especially postural stability, has a major impact on the goalkeeper's performance. The ability to maintain a balanced and stable posture is an important element of motor coordination. It also significantly affects the quality of the goalkeeper's movement.

The body composition of the goalkeepers in the current study was normal, which was indicative of proper nutrition and correct biological regeneration. The analysis of body composition is one of the most important elements regarding health assessment in sport.

As already mentioned, correct and stable posture is also a prerequisite for carrying out most free movements and those related to locomotion, and it has a considerable influence on the performance of a handball goalkeeper. In the test with eyes closed (CE), three postural parameters increased significantly: Average Load Point Y $(\mathrm{cm})$, Path Length $(\mathrm{cm})$, and Average COP Speed $(\mathrm{cm} / \mathrm{sec})$. Closing the eyes caused a significant reaction of the postural system to the difficulty. Since these parameters worsened in the test with closed eyes, this indicates that the ability to use the eyesight plays a role in the process of maintaining balance. There was proper coordination between the visual analyser and the postural system.

In the current study, analysing the relationship between body composition and postural stability, a number of direct correlations occurred. Fat Mass (\%) was significantly correlated with Area Ellipse $\left(\mathrm{cm}^{2}\right)(\mathrm{OE})$. Also, Fat Mass $(\mathrm{kg})$ correlated significantly with Area Ellipse $\left(\mathrm{cm}^{2}\right)(\mathrm{OE})$. This means that the level of Fat Mass significantly affects postural stability. The higher the level of Fat Mass, the worse the postural stability. Correspond- ingly, inverse correlations occurred between Fat-Free Mass (kg) and Average Load Point Y (cm) (OE) as well as Average Load Point Y (cm) (CE); the higher the Fat-Free Mass (kg) level was, the better the postural stability was. Muscle Mass (kg) was significantly inversely correlated with Average Load Point Y $(\mathrm{cm})$ $(\mathrm{OE})$ and also with Average Load Point Y (cm) (CE); the higher the level of Muscle Mass ( $\mathrm{kg}$ ), the better the postural stability. The Body Mass Index inversely correlated with Average Load Point Y $(\mathrm{cm})(\mathrm{CE})$, higher BMI being associated with better the postural stability. Total Body Water $(\mathrm{kg})$, was significantly inversely correlated with Average Load Point Y (cm) (OE), and also with Average Load Point Y (cm) (CE). Nonetheless, Total Body Water (\%) only correlated negatively with Area Ellipse $\left(\mathrm{cm}^{2}\right)(\mathrm{OE})$. The higher the Total Body Water level was, the better the postural stability was (Tab. 3).

Postural stability is associated with inertial forces acting on the body and inertial characteristics of body segments. Therefore, postural stability is determined by body composition and structure $[20,21]$. In the literature, it is difficult to find similar studies in which body composition would be assessed with Tanita electrical bioimpedance and postural stability with AccuGait AMTI. The purpose of a similar study was to establish the main morphological characteristics of Slovenian junior and senior female national handball team players. Morphological characteristics of various player subgroups (goalkeepers, wings, back players, and pivots) were also determined so as to establish whether they had distinct profiles [22]. The authors of this research found that groups of handball players occupying different positions differed amongst themselves in terms of many measurements. This is the result of the specific requirements placed on handball players. The tallest players should thus be oriented to back playing positions. Regarding pivots, apart from body height, the coaches must consider robustness. For goalkeepers, body height is very important; the robustness criteria, however, are slightly lower. For wings, body height is not a decisive factor, and smaller players can also occupy this position. Both of the above criteria (also taking other ones into account) facilitate coaches' decisions when players are selected for particular playing positions [22]. The purpose of another study was to compare the morphology and physical fitness of 104 male handball athletes under the age of 16 with different competitive levels with respect to their bone maturation. In their conclusions, the authors of this study stated that maturation should be considered as a covariate when one intends to explore the morphological characteristics and physical fitness of athletes below the age of 16 with different levels of practice [23]. The aims of the next study were to describe the body structure and morphological characteristics of Tunisian elite handball players and to determine the effect of these variables on functional and physical performance levels. The results of this research indicate that morphological and physical characteristics correlate strongly with functional characteristics. In handball, it is possible to have a reliable estimate of anthropometric measurements and physical as well as physiological performance [24]. The aim of a different study was to investigate the influence of major professional sport disciplines, such as handball, gymnastics, swimming, and shooting, on the subsystems of postural control. The hypothesis that specific types of sport have specific effects on postural regulation was also tested. Different types of competitive sports exert different effects on the various subsystems of posture control, where especially shooting competitors demonstrate significantly better postural regulation [25]. The purpose of another work was to analyse the relationships between body posture, postural stability parameters, and body composition in 
goalkeepers of the Polish National Junior Handball Team. Body posture was evaluated using the Diers Formetric III 4D optoelectronic method. Postural stability was examined with the Biodex Balance System platform. The flattening of the thoracic kyphotic and lumbar lordotic angle was observed. The majority of adolescents in the study had residual scoliosis. During the Postural Stability Test, all of them remained in Zone A (the best stability), and in the majority of cases, they had a tendency towards right posterior sways (\% Time in Quadrant 1). A positive correlation was found between trunk length from vertebra C7 to the central point between the sacral dimples as well as trunk length VP-SP from C7 to the beginning of the groove between the buttocks and the percentage of time in Quadrant 1 (\% Time in Quadrant 1), that is sway to the right anterior. Most of the respondents began training between the ages of 12 and 13 , that is during a period when they were particularly susceptible to changes in body posture due to the acceleration of skeletal system development with simultaneous slower development of other systems, mainly the muscle-ligament-joint and nervous systems [26]. Single-sided sports specialisation can lead to static disorders in this developmental period. Therefore, systematic tests are needed to monitor body composition and postural stability [27].

\section{Conclusions}

Correct and stable posture is a prerequisite for carrying out most free movements and those related to locomotion, and it plays a major role in the performance of a handball goalkeeper. The body composition of the subjects was correct. All subjects had very good postural stability. Greater postural sway was observed in the sagittal plane than the frontal one. Path Length and Average COP Speed were significantly increased during the closed eyes test. Only Fat Mass (\%) and Fat Mass (kg) were significantly directly correlated with Area Ellipse $\left(\mathrm{cm}^{2}\right)(\mathrm{OE})$. Inverse correlations occurred between Fat-Free Mass (kg) and Average Load Point Y (cm) (OE) as well as Average Load Point $\mathrm{Y}(\mathrm{cm})(\mathrm{CE})$. Muscle Mass (kg) was significantly inversely correlated with Average Load Point Y $(\mathrm{cm})(\mathrm{OE})$ and also with Average Load Point Y (cm) (CE). Body Mass Index correlated negatively only with Average Load Point Y (cm) (CE). Total Body Water $(\mathrm{kg})$ was significantly inversely correlated with Average Load Point Y (cm) (OE) and also with Average Load Point Y (cm) (CE). However, Total Body Water (\%) only correlated negatively with Area Ellipse $\left(\mathrm{cm}^{2}\right)$ (OE). The higher the values of the body composition variables listed, the better the stability. Postural stability was determined by the composition and structure of the body. Single-sided sports specialisation can lead to static disorders in the developmental period discussed. Therefore, systematic tests are needed to monitor the body composition and postural stability of handball goalkeepers.

\section{Acknowledgements}

The research project was conducted in 2014-2018 in the Laboratory of Posturology at Jan Kochanowski University in Kielce, Faculty of Medicine and Health Sciences.

\section{Literature}

1. Baptista F., Barrigas C., Vieira F., Santa-Clara H., Homens P.M., Fragoso I. et al. (2012). The role of lean body mass and physical activity in bone health in children. Jo- urnal of Bone and Mineral Metabolism 30(1), 100-8. DOI: 10.1007/s00774-011-0294-4.

2. Ingebrigtsen J., Jeffreys I., Rodahl S. (2013). Physical characteristics and abilities of junior elite male and female handball players. Journal of Strength $\mathcal{E}$ Conditioning Research 27(2), 302-9. DOI: 10.1519/JSC. Ob0 13e318254899f.

3. Hernández-Davó J.L., Sabido R., Behm D.G., Blazevich A.J. (2018). Effects of resistance training using known vs unknown loads on eccentric-phase adaptations and concentric velocity. Scandinavian Journal of Medicine E Science in Sports 28(2), 407-417. DOI: 10.1111/sms.12933.

4. Mohamed H., Vaeyens R., Matthys S., Multael M., Lefevre J., Lenoir M. et al. (2009). Anthropometric and performance measures for the development of a talent detection and identification model in youth handball. Journal of Sports Sciences 27(3), 257-66. DOI:10.1080/02 640410802482417.

5. Schwesig R., Hermassi S., Fieseler G., Irlenbusch L., Noack F., Delank K.S. et al. (2017). Anthropometric and physical performance characteristics of professional handball players: Influence of playing position. Journal of Sports Medicine and Physical Fitness 57(11), 1471-1478. DOI: 10.23736/S0022-4707.

6. Ilic V., Ranisavljev I., Stefanovic D., Ivanovic V., Mrdakovic V. (2015). Impact of body composition and Vo2 max on the competitive success in top-level handball players. Collegium Antropologicum 39(3), 535-40.

7. Dobbin N., Gardner A., Daniels M., Twist C. (2018). Theinfluence of ' preseason training phase and training load on body composition and its relationship with physical qualities in professional junior rugby league players. Journal of Sports Sciences 8, 1-9. DOI: 10.1080/02640414.2018.1473993.

8. Lee L.W., Liao Y.S., Lu H.K., Hsiao P.L., Chen Y.Y., Chi C.C. et al. (2017). Validation of two portable bioelectrical impedance analyses for the assessment of body composition in school age children. PLoS One 12(2), e0171568. DOI: 10.1371/journal.pone.0171568.

9. Cavala M., Trninić V., Jasić D., Tomljanović M. (2013). The influence of somatotype components and personality traits on the playing position and the quality of top Croatian female cadet handball players. Collegium Antropologicum 37(2), 93-100.

10. Bon M., Pori P., Sibila M. (2015). Position-related differences in selected morphological body characteristics of toplevel female handball players. Collegium Antropologicum 39(3), 631-9.

11. Missawi K., Zouch M., Chakroun Y., Chaari H., Tabka Z., Bouajina E. (2016). Handball practice enhances bone mass in specific sites among prepubescent boys. Journal of Clinical Densitometry 19(3), 389-95. DOI: 10.1016/j. jocd.2016.04.008.

12. Grabara M. (2017). The posture of adolescent male handball players: A two-year study. Journal of Back and Musculoskeletal Rehabilitation 31(1), 183-189. DOI: 10.3233/BMR-170792.

13. Ashtiani M.N., Mahmood-Reza A. (2017). Nonlinear dynamics analysis of the human balance control subjected to physical and sensory perturbations. Acta Neurobiologiae Experimentalis 77(2), 168-175.

14. Fugiel J., Sławińska T. (2012). Body posture of children of early sport specialization. Journal of Kinesiology and Exercise Sciences 53, 79-83.

15. Lichota M., Plandowska A., Mil P. (2011). The shape of anterior-posterior curvatures of the spine in athletes practising selected sports. Polish Journal of Sport and Tourism 18(2), $112-116$. 
16. Steib S., Zahn P., Zu Eulenburg C., Pfeifer K., Zech A. (2016). Time-dependent postural control adaptations following a neuromuscular warm-up in female handball players: A randomized controlled trial. BMC Sports Science, Medicine and Rehabilitation 8, 33.

17. Daneshfar A., Gahreman D.E., Koozehchian M.S., Amani Shalamzari S., Hassanzadeh Sablouei M., Rosemann T. et al. (2018). Multi-directional repeated sprint is a valid and reliable test for assessment of junior handball players. Frontiers in Physiology 9, 317. DOI: 10.3389/fphys. 2018.00317.

18. Jadczak Ł., Grygorowicz M., Dzudziński W., Śliwowski R. (2018). Comparison of static and dynamic balance at different levels of sport competition in professional and junior elite soccer players. Journal of Strength $\mathcal{E}$ Conditioning Research 12. DOI: 10.1519/JSC00 00000000002476.

19. Powell D.W., Williams D.S. (2015). Athletes trained using stable compared to unstable surfaces exhibit distinct postural control profiles when assessed by traditional and nonlinear measures. Human Movement Science 44, 73-80. DOI: 10.1016/j.humov.2015.08.013.

20. Gebel A., Lesinski M., Behm D.G., Granacher U. (2018). Effects and dose-response relationship of balance training on balance performance in youth: A systematic review and meta-analysis. Sports Medicine 7. DOI: 10.1007/s40279018-0926-0.

21. Santos L., Fernández-Río J., Iglesias-Soler E., BlancoTraba M., Jakobsen M.D., González-Díez V. et al. (2018). Postural control and physiological responses to a simulated match in U-20 judo competitors. Sports Biomechanics 21, 1-14. DOI: 10.1080/14763141.2018.1461237.

22. Sibila M., Pori P. (2009). Position-related differences in selected morphological body characteristics of top-level handball players. Collegium Antropologicum 33(4), 107986.

23. Vieira F., Veiga V., Carita A.I., Petroski E.L. (2013). Morphological and physical fitness characteristics of under-16 Portuguese male handball players with different levels of practice. Journal of Sports Medicine and Physical Fitness 53(2), 169-76.

24. Moncef C., Said M., Olfa N., Dagbaji G. (2012). Influence of morphological characteristics on physical and physiological performances of Tunisian elite male handball players. Asian Journal of Sports Medicine 3(2), 74-80.

25. Schwesig R., Kluttig A., Leuchte S., Becker S., Schmidt H., Esperer H.D. (2009). The impact of different sports on posture regulation. Sportverletz Sportschaden 23(3), 148-54. DOI: 10.1055/s-0028-1109576.

26. Wilczyński J., Dutkiewicz R., Wilczyński I. (2016). Body posture, postural stability and body composition in goalkeepers of Polish National Junior Handball Team. Journal of Kinesiology and Exercise Sciences 76, 11-20.

27. van Cingel R., Habets B., Willemsen L., Staal B. (2018). Shoulder dynamic control ratio and rotation range of motion in female junior elite handball players and controls. Clinical Journal of Sport Medicine 28(2), 153-158. DOI: 10.1097/ JSM.0000000000000429.

Submitted: April 16, 2018

Accepted: June 5, 2018 